\title{
THERMAL DECOMPOSITION OF TETRACYCLINE AND CEPHALOSPORINS METAL COMPLEXES
}

\author{
A. A. M. Aly, A. H. Osman, N. Abo El-Maali and G. A. A. Al-Hazmi \\ Department of Chemistry, Faculty of Science, Assiut University, Assiut, Egypt

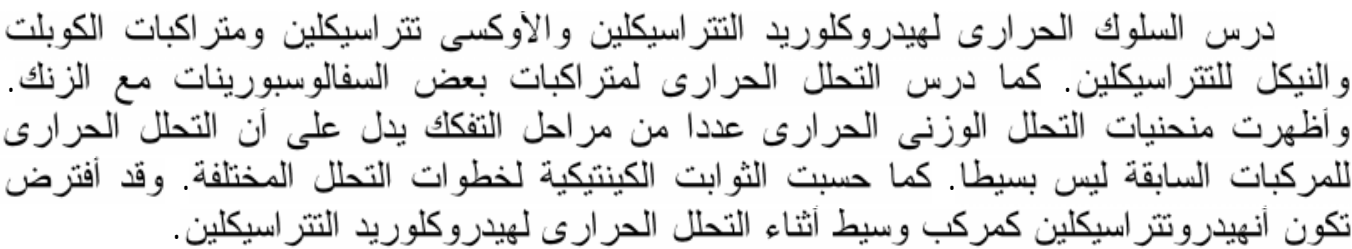

Thermal behaviour of tetracycline hydrochloride, oxytetracycline dihydrate, Co(II) and $\mathrm{Ni}(I I)$ complexes of tetracycline and $\mathrm{Zn}(\mathrm{II})$ complexes of some cephalosporin antibiotics, namely cephalexin, cephapirin, cefuroxime, and ceftazidime was studied using thermogravimetric analysis $(T G)$.

The TG curves exhibit several thermal events indicating that the thermal decomposition of these compounds are not simple. The kinetic parameters for steps appropriate for kinetic analysis were evaluated making use of the Coats-Redfern equation. During the thermal decomposition of tetracycline hydrochloride anhydrotetracycline was proposed to be formed as an intermediate due to the elimination of water.

\section{INTRODUCTION}

Tetracycline and its derivatives are widely used in human and veterinary medicine as antibiotics that depress protein synthesis by blocking the aminoacetyl-tRNA binding. ${ }^{1}$ It is now established that some of the biological effects of tetracyclines arise from their interactions with metal ions. ${ }^{2}$ Tetracycline antibiotics function as chelating ligands to main group and transition metals. ${ }^{3-5}$ Absorption and therapeutic action of tetracyclines are reduced if the patient is taking milk, which contains $\mathrm{Ca}^{2+}$ or antacids which contain di or trivalent metals or is being prescribed iron salts for anaemia. ${ }^{6}$ These effects have been ascribed to the formation of complexes between the drugs and various metal ions.

Furthermore, cephalosporin antibiotics are the most important class of drugs against infectious diseases caused by bacteria ${ }^{7,8}$ and their interactions in human body were recently studied. $^{9,10}$ The biological activity of these antibiotics is attributed to the $\beta$-lactam ring. ${ }^{11}$

In view of the above mentioned coordination properties of tetracyclines and cephalosporins, the development of new and more active drugs requires that the stability and the energetic features of the formed metal complexes be known beforehand. Therefore, the thermal behaviour of tetracycline hydrochloride, oxytetracycline dihydrate, $\mathrm{Co}$ (II) and $\mathrm{Ni}$ (II) complexes of tetracycline and $\mathrm{Zn}$ (II) complexes of some cephalosporins was investigated.

\section{EXPERIMENTAL}

All chemicals were of analytical grade. Tetracycline hydrochloride (Aldrich) and oxytetracycline dihydrate (Sigma) were used as purchased. Cephalexin (CID, Egypt) and the sodium salts of cephapirin (Bristol-Myers Squibb Co., New York), cefuroxime and ceftazidime (Glaxo Wellcome, UK) were used as purchased. Name, notation and structure of the cephalosporins under investigation are given in Table 1. The $\mathrm{Co}(\mathrm{II})$ and $\mathrm{Ni}(\mathrm{II})$ tetracycline complexes ${ }^{12}$ and $\mathrm{Zn}$ (II) cephalosporins ${ }^{13}$ were prepared according to recommended literature procedures. 
Table 1: Name, notation and structure of the antibiotics under investigation.<smiles>[R]C(=O)N[C@@H]1C(=O)N2C(C(=O)O)=C([R])CS[C@@H]12</smiles>

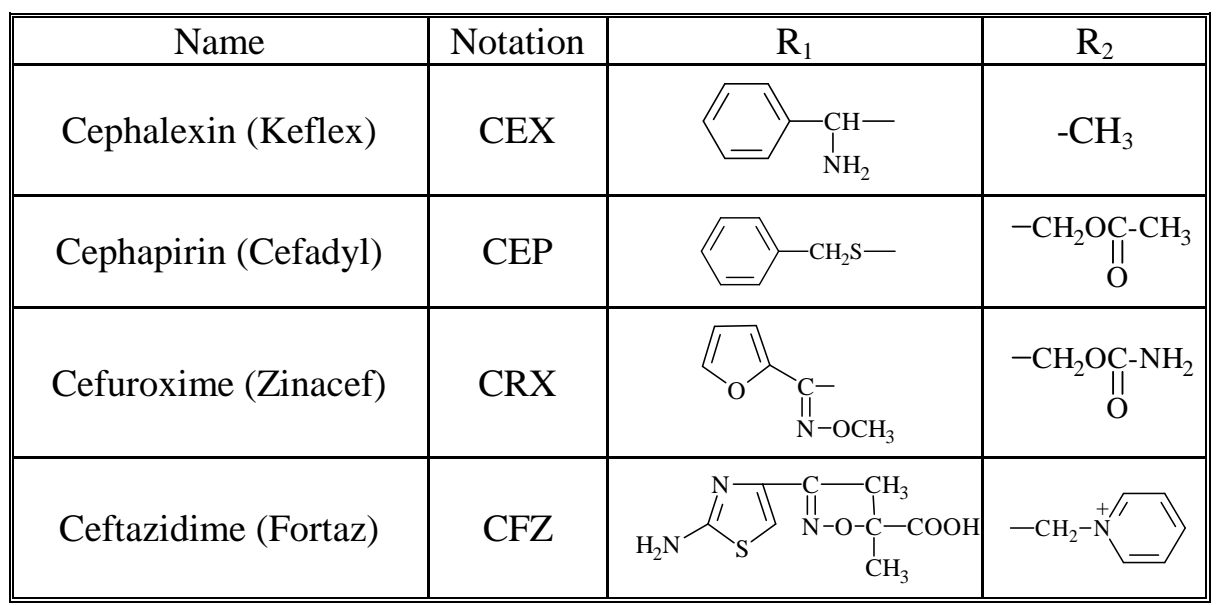

The thermal studies were carried out in dynamic air $\left(30 \mathrm{~mL} \mathrm{~min}^{-1}\right)$ on a DuPont 2000 thermal analyser. Working conditions include: heating rate of $10^{\circ} \mathrm{min}^{-1}$, temperature range from ambient temperature to $700^{\circ}$, sample mass of about 8-10 mg and using a flat-boat platinum crucible.

\section{RESULTS AND DISCUSSION}

The thermal properties of tetracycline hydrochloride, oxytetracycline dihydrate, Co(II) and $\mathrm{Ni}$ (II) complexes of tetracycline and $\mathrm{Zn}$ (II) cephalosporin complexes were studied in dynamic air. Their TG and DTG curves are depicted in Figures 1-4. The kinetic parameters of decomposition are tabulated in Tables 1 and 2.

\section{Tetracycline hydrochloride $\left(\mathrm{C}_{22} \mathrm{H}_{24} \mathrm{~N}_{2} \mathrm{O}_{8}\right.$. $\left.\mathrm{HCl}\right)$}

Tetracycline hydrochloride undergoes a stepwise decomposition in three steps well discernible in the TG and DTG curves in the temperature ranges $233-260,260-286$ and 386$570^{\circ}$. A small step of weight loss $1.3 \%$ at about $100^{\circ}$ is attributed to adsorbed water. The mass loss at the first step points to the elimination of

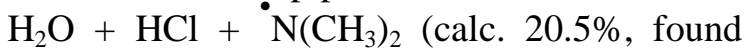
$21.3 \%$ ). The second step corresponds to a mass loss of $13.0 \%$ while the third step represents the major mass loss $(63.1 \%)$. It is assumed that anhydrotetracycline (II) is formed after elimination of $\mathrm{H}_{2} \mathrm{O}$ and $\mathrm{HCl}$ then losing the radical $\mathrm{N}\left(\mathrm{CH}_{3}\right)_{2}$ leaving (III) which decomposes in the second and third steps (Scheme 1).<smiles>CN(C)C1C(O)=C(C(N)=O)C(=O)[C@@]2(O)C1=C1C(=O)c3c(O)cccc3C(C)(O)C1C[C@H]2O</smiles>

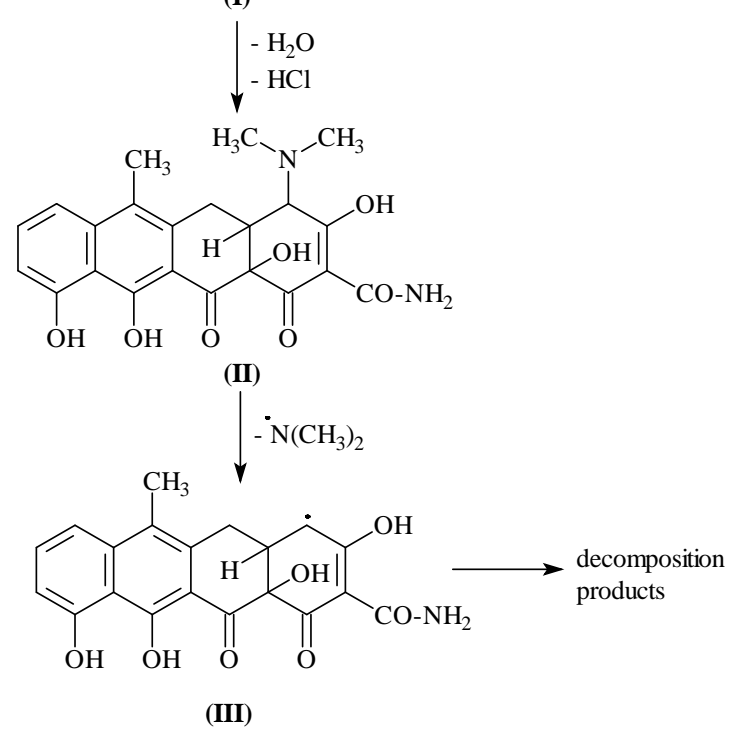

Scheme 1 


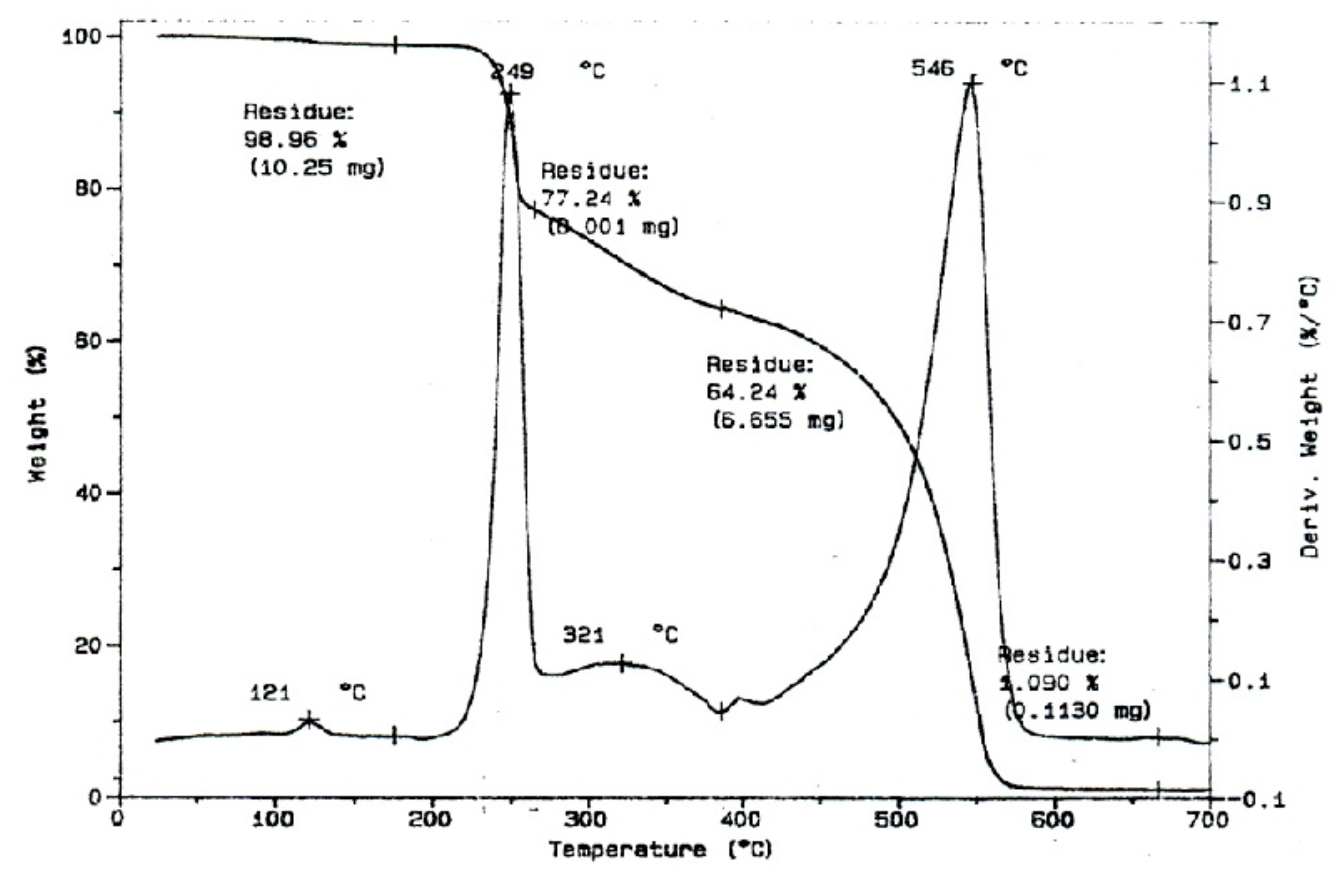

Fig. 1: TG and DTG curves of tetracycline hydrochloride.

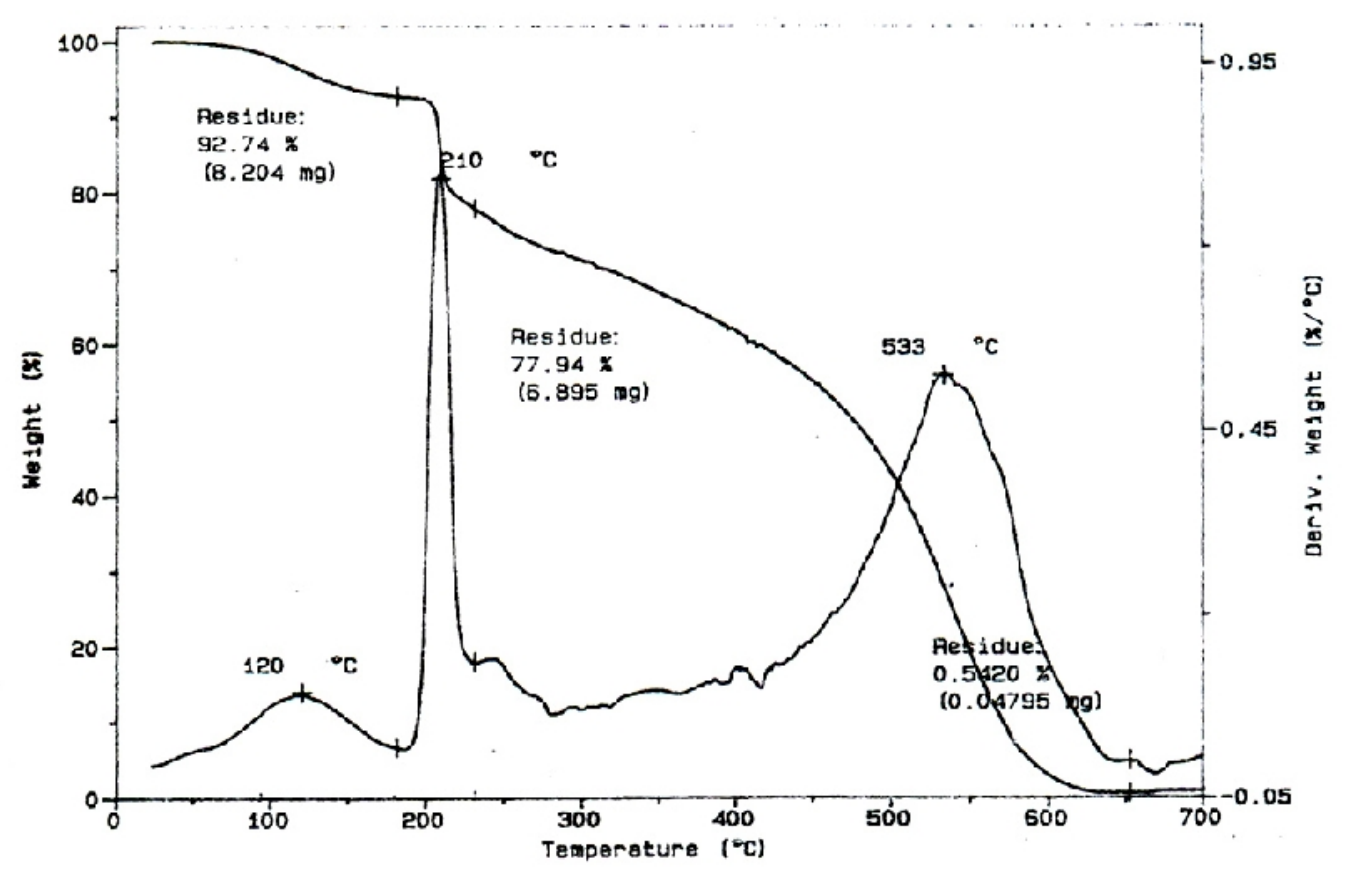

Fig. 2: TG and DTG curves of oxytetracycline dihydrate. 


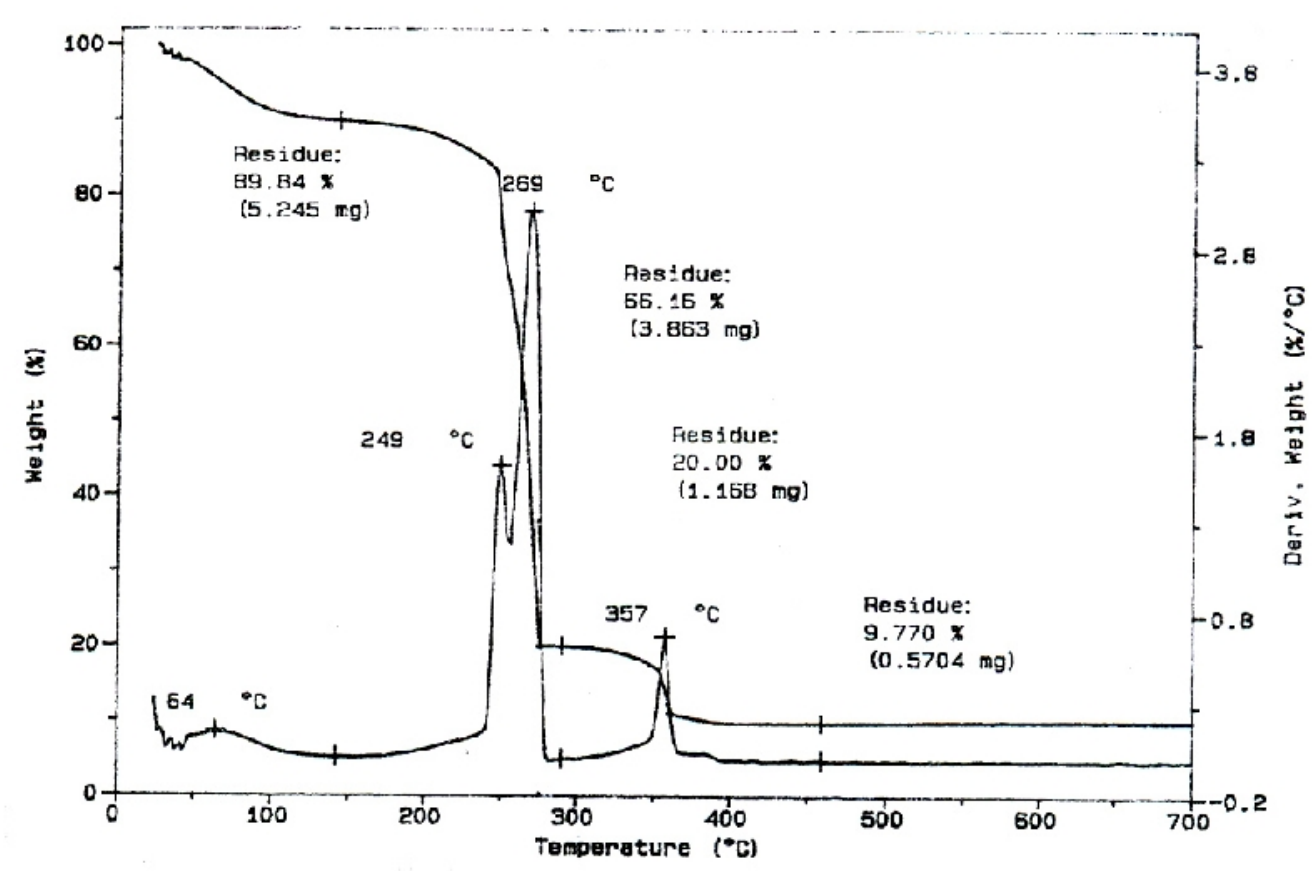

Fig. 3: TG and DTG curves of bis(tetracycline)nickel(II)dihydrate.

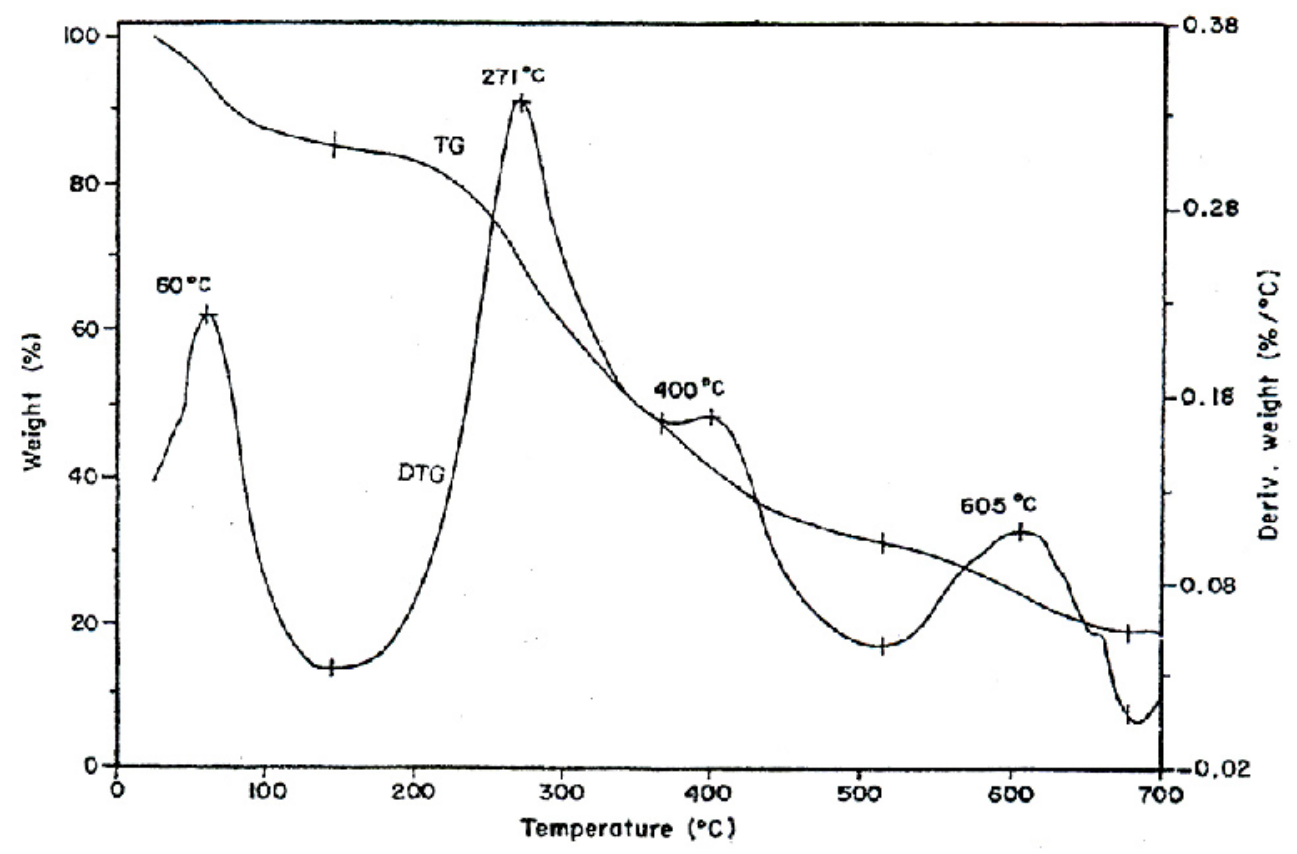

Fig. 4: TG and DTG curves of $\left[\mathrm{Zn}_{2} \mathrm{Cl}_{2}(\mathrm{CFZ})\left(\mathrm{H}_{2} \mathrm{O}\right)\right] \cdot 3 \mathrm{H}_{2} \mathrm{O}$. 
Table 2: Kinetic parameters of the thermal decomposition of tetracycline hydrochloride and $\mathrm{Zn}$ (II) cephalosporins complexes.

\begin{tabular}{|c|c|c|c|c|}
\hline Compound & Step & $\mathrm{r}$ & $\mathrm{n}$ & $\begin{array}{c}E \\
\mathrm{E} \\
(\mathrm{kJ} / \mathrm{mol})\end{array}$ \\
\hline \multirow{10}{*}{ Tetracycline hydrochloride } & \multirow[t]{5}{*}{$1^{\text {st }}$ step } & $\underline{0.9810}$ & 0.00 & 193 \\
\hline & & 0.9774 & 0.33 & 242 \\
\hline & & 0.9751 & 0.5 & 262 \\
\hline & & 0.9728 & 0.66 & 282 \\
\hline & & 0.9672 & 1.00 & 328 \\
\hline & \multirow[t]{5}{*}{$3^{\text {rd }}$ step } & 0.9958 & 0.00 & 116 \\
\hline & & 0.9977 & 0.33 & 137 \\
\hline & & 0.9982 & 0.5 & 150 \\
\hline & & $\underline{0.9984}$ & 0.66 & 162 \\
\hline & & $\overline{0.9980}$ & 1.00 & 190 \\
\hline \multirow{10}{*}[\mathrm{ZnCl}(\mathrm{CEX})(\mathrm{H}_{2}\mathrm{O})]{$\cdot 2 \mathrm{H}_{2} \mathrm{O}$} & \multirow[t]{5}{*}{$1^{\mathrm{st}}$} & 0.9719 & 0.00 & 16 \\
\hline & & 0.9873 & 0.33 & 21 \\
\hline & & 0.9839 & 0.50 & 24 \\
\hline & & 0.9888 & 0.66 & 27 \\
\hline & & $\underline{0.9920}$ & 1.00 & 34 \\
\hline & \multirow[t]{5}{*}{$2^{\text {nd }}$} & 0.9946 & 0.00 & 76 \\
\hline & & 0.9971 & 0.33 & 84 \\
\hline & & 0.9979 & 0.50 & 88 \\
\hline & & 0.9978 & 0.66 & \\
\hline & & 0.9973 & 1.00 & \\
\hline \multirow{10}{*}[\mathrm{ZnCl}(\mathrm{CEP})(\mathrm{H}_{2}\mathrm{O})]{$\cdot 2 \mathrm{H}_{2} \mathrm{O}$} & \multirow[t]{5}{*}{$1^{\text {st }}$} & 0.9854 & 0.00 & 18 \\
\hline & & 0.9876 & 0.33 & 21 \\
\hline & & 0.9880 & 0.50 & 23 \\
\hline & & 0.9883 & 0.66 & 25 \\
\hline & & $\underline{0.9884}$ & 1.00 & 29 \\
\hline & \multirow[t]{5}{*}{$2^{\text {nd }}$} & $\underline{0.9990}$ & 0.00 & 62 \\
\hline & & 0.9986 & 0.33 & 68 \\
\hline & & 0.9979 & 0.50 & 72 \\
\hline & & 0.9971 & 0.66 & 75 \\
\hline & & 0.9945 & 1.00 & 82 \\
\hline \multirow{5}{*}[\mathrm{Zn}(\mathrm{CRX})]{$\cdot 3 \mathrm{H}_{2} \mathrm{O}$} & \multirow[t]{5}{*}{$1^{\text {st }}$} & 0.9851 & 0.00 & 21 \\
\hline & & 0.9911 & 0.33 & 24 \\
\hline & & 0.9929 & 0.50 & 27 \\
\hline & & 0.9948 & 0.66 & 28 \\
\hline & & $\underline{0.9973}$ & 1.00 & 33 \\
\hline \multirow{10}{*}[\mathrm{Zn}_{2}\mathrm{Cl}_{2}(\mathrm{CFZ})(\mathrm{H}_{2}\mathrm{O})]{$\cdot 2 \mathrm{H}_{2} \mathrm{O}$} & \multirow[t]{5}{*}{$1^{\mathrm{st}}$} & $\overline{0.9785}$ & 0.00 & 27 \\
\hline & & 0.9855 & 0.33 & 30 \\
\hline & & 0.9882 & 0.50 & 32 \\
\hline & & 0.9907 & 0.66 & 34 \\
\hline & & $\underline{0.9943}$ & 1.00 & 38 \\
\hline & \multirow[t]{5}{*}{$2^{\text {nd }}$} & $\underline{0.9965}$ & 0.00 & 53 \\
\hline & & 0.9951 & 0.33 & 57 \\
\hline & & 0.9948 & 0.50 & 59 \\
\hline & & 0.9940 & 0.66 & 60 \\
\hline & & 0.9927 & 1.00 & 64 \\
\hline
\end{tabular}




\section{Oxytetracycline $\left(\mathrm{C}_{22} \mathrm{H}_{24} \mathrm{~N}_{2} \mathrm{O}_{9} .2 \mathrm{H}_{2} \mathrm{O}\right)$}

The pyrolysis curve of oxytetracycline dihydrate consists of three decomposition steps in the temperature ranges 94-180, 180-230 and $230-620^{\circ}$. The first step is commensurate with the elimination of $2 \mathrm{H}_{2} \mathrm{O}$ molecules (calc. $7.3 \%$, found $7.3 \%$ ). The second step corresponds to the expulsion of the radical $\mathrm{N}\left(\mathrm{CH}_{3}\right)_{2}$. The third step is a major step with a mass loss of $82.3 \%$.

\section{Bis(tetracycline)diaquocobalt(II) $\quad\left(\mathrm{C}_{44} \mathrm{H}_{46} \mathbf{N}_{4^{-}}\right.$ $\left.\mathrm{O}_{16}\right) \mathrm{Co}(\mathrm{II}) .2 \mathrm{H}_{2} \mathrm{O}$}

The TG thermogram for this complex reveals three decomposition steps. The first step $\left(50-150^{\circ}\right)$ suggests expulsion of one water molecule and the radical $\mathrm{N}\left(\mathrm{CH}_{3}\right)_{2}$ (calc. $6.3 \%$, found $6.3 \%$ ). The second step appears in the temperature range $140-290^{\circ}$. The third step seems to be composed of two strongly overlapped steps well separated in the DTG curve at 339 and $347^{\circ}$. The residue (11.9\%) is greater than the calculated for $\mathrm{CoO}(7.6 \%)$ or $\mathrm{Co}_{3} \mathrm{O}_{4}(8.1 \%)$ indicating that part of the liberated carbon is included in the residue.

\section{Bis(tetracycline)diaquonickel(II) $\quad\left(\mathrm{C}_{44} \mathrm{H}_{46} \mathbf{N}_{4^{-}}\right.$ $\left.\mathrm{O}_{16}\right) \mathrm{Ni}(\mathrm{II}) .2 \mathrm{H}_{2} \mathrm{O}$}

The stepwise course of the pyrolysis curve of the complex is characterised by three decomposition steps in the temperature ranges 50-110, $150-276$ and $276-400^{\circ}$. The first step involves elimination of $2 \mathrm{H}_{2} \mathrm{O}+\mathrm{N}\left(\mathrm{CH}_{3}\right)_{2}$ (calc. $8.2 \%$, found $8.6 \%$ ). The second step is composed of two overlapped steps (at 249 and $269^{\circ}$, DTG curve). The main mass loss of the ligand takes place during this step (70.9\%). The third step is accompanied with a mass loss of $10.2 \%$. The residual mass $(9.7 \%)$ is somewhat greater than calculated for $\mathrm{NiO}$ (7.6\%). It is possible to suggest that part of carbons is included in the residue.

The thermal decomposition of the $\mathrm{Zn}$ (II) cephalosporins was reported previously. ${ }^{13}$ However, no kinetic analysis of the thermal curves was attempted. This will be done in this investigation. Before one can proceed to such analysis a brief description of the thermal behaviour of the four investigated $\mathrm{Zn}$ (II) complexes is indicated as follows: The TG curve of $\left[\mathrm{ZnCl}(\mathrm{CEX})\left(\mathrm{H}_{2} \mathrm{O}\right)\right] \cdot 2 \mathrm{H}_{2} \mathrm{O}$ shows six overlapping steps; however, the first and second steps are well defined in the temperature ranges $29-143^{\circ}$ and $168-289^{\circ}$. The pyrolysis curve of $\left[\mathrm{ZnCl}(\mathrm{CEP})\left(\mathrm{H}_{2} \mathrm{O}\right)\right] \cdot 2 \mathrm{H}_{2} \mathrm{O}$ exhibits three steps of decomposition in the temperature ranges $40-145^{\circ}, 150-263^{\circ}$ and 263 $518^{\circ}$; the first step is commensurate with the release of two water molecules. The stepwise course of the TG curve of $\left[\mathrm{Zn}(\mathrm{CRX})_{2}\right] \cdot 3 \mathrm{H}_{2} \mathrm{O}$ is composed of four steps at $45-124^{\circ}, 130-238^{\circ}$, $276-286^{\circ}$ and $520-561^{\circ}$. The dehydration occurs at the first step with the evolution of three water molecules. The TG curve of $\left[\mathrm{Zn}_{2} \mathrm{Cl}_{2}(\mathrm{CFZ})\left(\mathrm{H}_{2} \mathrm{O}\right] \cdot 3 \mathrm{H}_{2} \mathrm{O}\right.$ consists of four steps at $28-136^{\circ}, 156-358^{\circ}, 358-506^{\circ}$ and $525-670^{\circ}$. The first step is consistent with the elimination of $3 \mathrm{H}_{2} \mathrm{O}+2 \mathrm{HCl}$.

\section{Non-isothermal kinetic analysis}

Non-isothermal kinetic analysis for the decomposition of tetracycline hydrochloride and $\mathrm{Zn}$ (II) cephalosporins was done with the application of the Coats-Redfern equation. ${ }^{14}$ The kinetic parameters E (activation energy) and $\mathrm{n}$ (order of the decomposition reaction) were evaluated only for clear-cut and nonoverlapping stages. Kinetic studies were not attempted as well for decomposition stages which occur within a very narrow temperature range, resulting in a TG curve too steep for enough data to be collected. In the following is the Coats-Redfern equation written in case of $n$ $\neq 1$ and $\mathrm{n}=1$ :

$$
\begin{aligned}
& \ln \left[\frac{1-(1-\alpha)^{1-n}}{(1-n) T^{2}}\right]=M / T+B \text { for } n \neq 1 \\
& \ln \left[\frac{-\ln (1-\alpha)}{T^{2}}\right]=M / T+B \text { for } n=1
\end{aligned}
$$

where $\alpha$ is the fraction of material decomposed, $\mathrm{n}$ is the order of the decomposition reaction and $\mathrm{M}=\mathrm{E} / \mathrm{R}$ and $\mathrm{B}=$ $\mathrm{ZR} / \phi \mathrm{E}$; where, $\mathrm{R}, \mathrm{Z}$ and $\phi$ are the gas constant, pre-exponential factor and heating rate, respectively.

The correlation coefficient $r$ is computed using the least squares method for equations (1) and (2). Linear curves were drawn for different values of $n$ ranging from 0 to 1 . The value of $n$, which gave the best fit, was chosen as the order parameter for the decomposition stage of interest. The kinetic parameters $n$ and E were calculated from the plots of the left hand side of equations (1) and (2) against 1/T. Table 2 includes the kinetic parameters of the 
thermal decomposition of tetracycline hydrochloride and $\mathrm{Zn}$ (II) cephalosporins.

Figure 5 illustrates the Coats-Redfern plots for $\left[\mathrm{ZnCl}(\mathrm{CEX})\left(\mathrm{H}_{2} \mathrm{O}\right)\right] \cdot \mathrm{H}_{2} \mathrm{O}$ for the first and second decomposition steps.

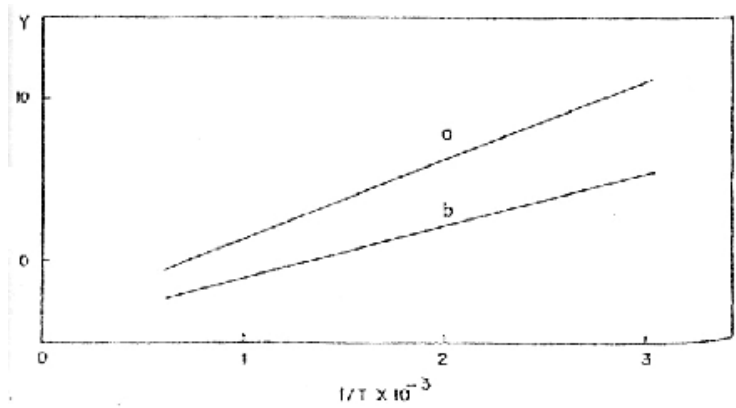

Fig. 5: Coats-Redfern plots for $[\mathrm{ZnCl}(\mathrm{CEX})$ $\left.\left(\mathrm{H}_{2} \mathrm{O}\right)\right] \cdot \mathrm{H}_{2} \mathrm{O}$, a) first step,

b) second step; where

$\mathrm{Y}=\ln \left[\frac{1-(1-\alpha)^{1-\mathrm{n}}}{(1-\mathrm{n}) \mathrm{T}^{2}}\right] \quad$ for $\mathrm{n} \neq 1$,

$\mathrm{Y}=\ln \left[\frac{-\ln (1-\alpha)}{\mathrm{T}^{2}}\right] \quad$ for $\mathrm{n}=1$

Figure 6 shows a regenerated thermogravimetric curve of $\left[\mathrm{ZnCl}(\mathrm{CEP})\left(\mathrm{H}_{2} \mathrm{O}\right)\right] \cdot \mathrm{H}_{2} \mathrm{O}$ calculated by means of the Coats-Redfern equation using the experimental values of the non-isothermal parameters, plotted in coordinates $\alpha, t\left(^{\circ}\right)$. The experimental points lie practically on the same curve, which indicates the accuracy of the Coats-Redfern equation. The fractionary values of the decomposition reaction order (n) in tetracycline hydrochloride or the cephalosporins $\mathrm{Zn}$ (II) complexes between zero and unity show a mixed regime of control (kinetic and diffusional) of the occurrence of the reaction, ${ }^{15,16}$ with the purely kinetic regime corresponding to $\mathrm{n}=1$.

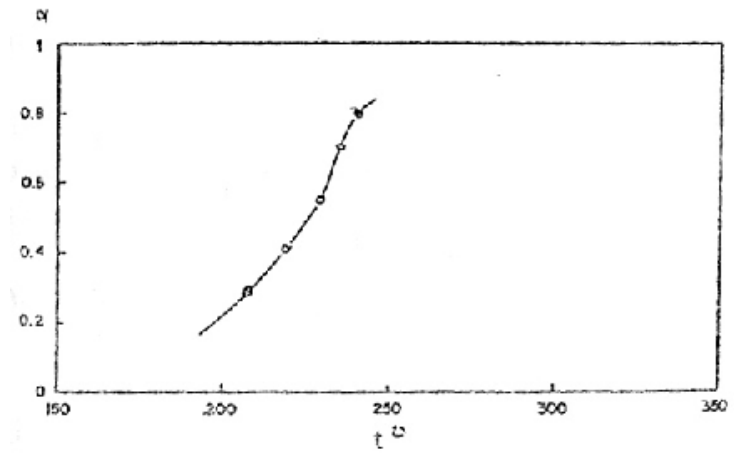

Fig. 6: Regenerated thermogravimetric curve of $\left[\mathrm{ZnCl}(\mathrm{CEP})\left(\mathrm{H}_{2} \mathrm{O}\right)\right] \cdot \mathrm{H}_{2} \mathrm{O}$.

( $\longrightarrow$ ) experimental, (o-o) calculated
In order to account for the mechanisms invoked in the dehydration of the compounds in this investigation, the following arguments should be taken into consideration:

- Dehydration of hydrate compound includes more than one type of chemical change upon heating: a) release of coordinated water can be regarded as a thermal decomposition of the complex compound,

b) dehydration accompanied by structural reorganization of a lattice destabilized by the removal of constituent hydrogen bonded water, c) hydroxyl groups that combine to give oxide and water.

- Discussion of dehydration frequently portrays the chemical changes as occurring within an active advancing interface and many investigations of dehydrations ${ }^{17}$ led to the recognition of the importance of the reaction interface in this respect. This is the zone, in the immediate vicinity of the contact between reactant and product phases, within which chemical changes occur preferentially.

- The constituent water in hydrates is usually regarded as participating in extensive structural hydrogen bonding and some or all may also be coordinated as a cation ligand. These local linkages must be important in characterizing the first step towards $\mathrm{H}_{2} \mathrm{O}$ release.

For most of the present investigated compounds the DTG peaks corresponding to the release of water of crystallization are broad or unsymmetrical indicating that the water molecules are not isoenergetically bound and some of them are involved in a structural hydrogen bonding. We assume that the dehydration in the present compounds leads to chemical changes in the complexes and occurs within an active reaction interface. Furthermore, Table 2 shows that the values of activation energies corresponding to the dehydrations of $\mathrm{Zn}$ (II) cephalosporins (the first decomposition stage for each compound) are somewhat larger than the range reported for water of crystallization, ${ }^{18}$ emphasizing involvement of water in hydrogen bonding.

Thorough examination of Table 2 reveals that the activation energies (for the second step) follow the following order for the three $\mathrm{Zn}(\mathrm{II})$ cephalosporins: $\left.\quad \mathrm{ZnCl}(\mathrm{CEX})\left(\mathrm{H}_{2} \mathrm{O}\right)\right]$ $.2 \mathrm{H}_{2} \mathrm{O}>\left[\mathrm{ZnCl}(\mathrm{CEP})\left(\mathrm{H}_{2} \mathrm{O}\right)\right] \cdot 2 \mathrm{H}_{2} \mathrm{O}>\left[\mathrm{Zn}_{2} \mathrm{Cl}_{2}\right.$ 
$\left.(\mathrm{CFZ})\left(\mathrm{H}_{2} \mathrm{O}\right)\right] \cdot 3 \mathrm{H}_{2} \mathrm{O}$. It seems that the size of the ligand plays an important role in the thermal stability of these complexes. More bulky substituents at $R_{1}$ and $R_{2}$ for the three ligands (see Table 1) lead to lower densities and consequently less effective packing. An increase of the density of compounds implies an increase in their thermal stability. ${ }^{19}$

The scanning electron micrographs of cephalexin and the $\mathrm{Zn}$ (II) cephalexin were done and shown in Fig. 7. The micrograph of the complex differ from that of the ligand (magnification is indicated under the figures). This difference may indicate formation of the $\mathrm{Zn}$ (II) complex. The ligand is crystalline and the crystals have the rod form and were $10 \mu \mathrm{m}$ in size.

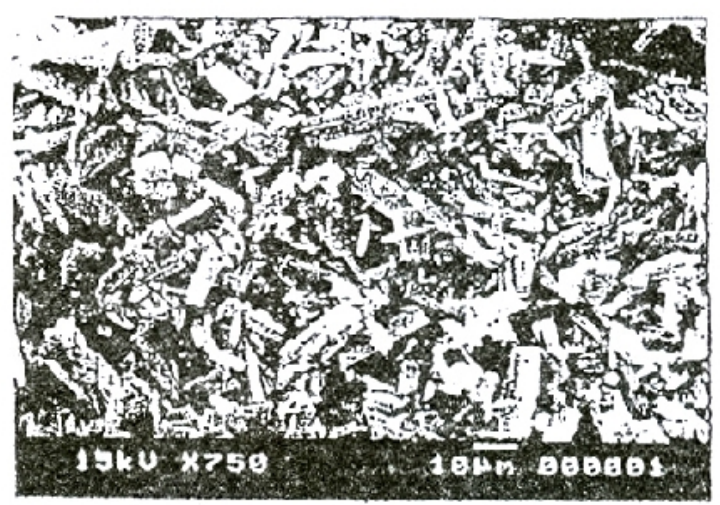

a.

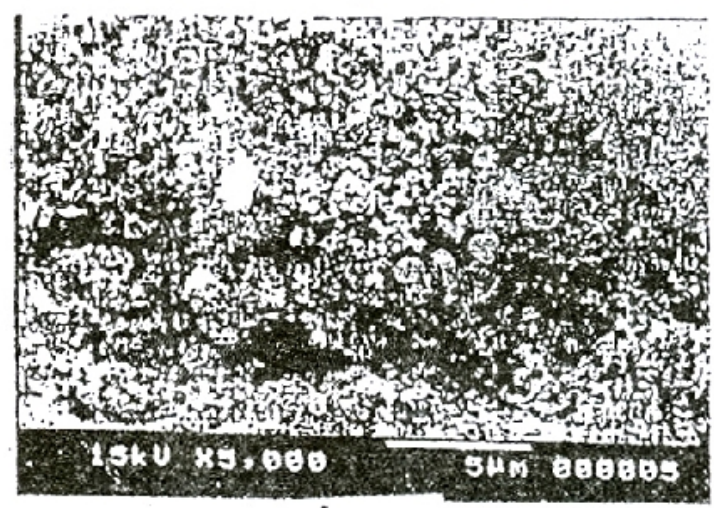

b)

Fig. 7: Scanning electron micrographs of a) cephalexin

b) $\left[\mathrm{ZnCl}(\mathrm{CEX})\left(\mathrm{H}_{2} \mathrm{O}\right)\right] \cdot \mathrm{H}_{2} \mathrm{O}$

\section{REFERENCES}

1- H. F. D. Santos, W. B. D. Almedia and M. C. Zerner, J. Chem. Soc., Perkin Trans., 2, 2519 (1998).

2- M. Brion, L. Lambs and G. Berthon, Inorg. Chim. Acta, 123, 61 (1986).

3- A. A. M. Aly, A. Strasser and A. Vogler, ibid., 336, 91 (2002).

4- A.A.M. Aly, Strasser and A. Vogler, Inorg. Chem. Comm., 5, 411 (2002).

5- M. Jezowska-Bojczuk, L. Lambs, H. Kozlowski, G. Berthon, Inorg. Chem., 32, 428 (1993), and references cited therein.

6- M. Riaz and N. Pilpel, J. Pharm. Pharmacol., 36, 153 (1983) and references therein.

7- A. Gringauz, "Introduction to Medicinal Chemistry", Wiley-VCH, Inc., New York, 1997, p. 216.

8- M. J. Schwaber, C. S. Garham, B. E. Sands, H. S. Gold and Y. Carmelia, Antimicrob. Agents Chemother., 47, 1882 (2003).

9- M. Takeda, E. Babu, S. Narikawa and H. Endou, Euro. J. Pharm., 438, 137 (2002).

10- S. Khamdang, M. Takeda, E. Babu, R. Noshiro, M. L. Onozata, A. Tojo, A. Enomoto, X. L. Huang, S. Narikawa, N. Anzai, P, Piyachaturawat and H. Endou, ibid., 465, 1 (2003).

11- L. P. Morelli, "Analytical Profile of Drug Substances", Vol. 4, Academic Press, 1975, p. 21.

12- W. A. Baker, Jr. and P. M. Brown, J. Am. Chem. Soc., 88, 1314 (1966).

13- A. A. M. Aly, A. H. Osman, N, Abo ElMaali and G. A. A. Al-Hazmi, J. Therm. Anal. Calor., 75, 159 (2004).

14- A. W. Coats and J. P. Redfern, Nature, 20, 68 (1964).

15- M. Badea and E. Segal, Thermochim. Acta, 149, 251 (1989).

16- E. Segal in V. V. Boldyrev and K. Meyer (Ed.), FestkÖrperchemie, VEB Deutscher Verlag Für Gründstoffindustrie, Leipzig, 1973, p. 404.

17- A. K. Galwey, Thermochim. Acta, 356, 181 (2000).

18- P. V. Khadikar, ibid., 127, 37 (1988).

19- P. Roman, J. I. Beitia, A. Luque and C. G.Miralles, Polyhedron, 13, 2311 (1994). 